\title{
EFFECTS OF EARLY-LIFE ANTIBIOTICS ADMINISTRATION ON THE IMMUNE RESPONSE TO NEWCASTLE DISEASE LASOTA VACCINATION AND WEIGHT INDICES OF BROILER CHICKEN
}

\author{
Madubuike, K. G. ${ }^{1}$, Okoroafor, O. N. ${ }^{2}$, Asuzu, I. U. ${ }^{3}$ \\ ${ }^{1}$ Department of Veterinary Physiology and Pharmacology \\ Michael Okpara University of Agriculture, Umudike \\ ${ }^{2}$ Department of Veterinary Medicine, University of Nigeria, Nsukka \\ ${ }^{3}$ Department of Veterinary Physiology and Pharmacology \\ University of Nigeria, Nsukka \\ Nigeria
}

madubuike.kelechi@mouau.edu.ng

\begin{abstract}
The administration of antibiotics to day old chicks as a means of prevention or treatment of suspected hatchery or farm-borne infections is common, especially in developing countries. This practice could contribute to a poor immune response following Newcastle disease (ND)-LaSota vaccinations, in addition to the sluggish growth in broiler chickens. This study was aimed at determining: the antibody titre to ND-LaSota vaccine, live weight, weight gain and feed conversion efficiency (FCE) of broiler chicken exposed early to gentamicin and doxycycline. One hundred, day-old broiler chicks were randomly assigned to four groups $(\mathbf{n}=25)$. Group 1 served as a control, while groups 2 and 4 received gentamycin and doxycycline, respectively. The chicks in group 3 were treated with a combination of gentamicin and doxycycline (1:1). All drugs were administered via the drinking water from the 2 nd to the 6 th day of the chicks' life. On day 18, the birds received ND-LaSota vaccine intraocularly. At weekly intervals, the post-vaccination antibody titre, live weight and weight gain were determined.
\end{abstract}

The feed conversion efficiency (FCE) of the different groups was calculated at the end of the experiments. The results showed that the NDV antibody titre of the antibiotic-treated groups did not differ significantly $(P<0.05)$ from that of the control. However, there was a significant $(P<0.05)$ increase in the live weight, weight gain and FCE of the control birds when compared to the antibiotic-treated groups.

Key words: antibody; doxycycline; gentamicin; titre; vaccination

\section{INTRODUCTION}

Several studies have shown that microbiota play a vital role in nutrient digestion and utilization [16, 17], as well as the modulation of innate $[9,12]$ and adaptive immune responses [11]. The colonization of the gut microbiota in young animals occurs simultaneously with the development of the gut tissues $[5,13,15]$; hence the disruption of gut microbiota as a result of early-life administration of 
antibiotics could contribute to poor immune responses to vaccines as well as diminished production [14].

Antibiotics have continued to be used widely in the poultry industry, especially in developing countries [21]. In Nigeria for instance, broad-spectrum antibiotics are routinely given to day-old chicks during the first 5-7 days of their lives as a way of combating infections suspected to be hatchery-borne or already established in the brooding houses. This practice could be responsible for the observed poor antibody titre following Newcastle disease LaSota vaccination as well as sub-optimal levels of growth and productivity in poultry [3]. The possible outcomes of the above scenario include: outbreaks of Newcastle disease in vaccinated flocks, too frequent revaccination of birds against the disease, and increased cost of production on the part of poultry farmers $[1,3,26]$.

The information on the effects of early-life administration of antibiotics on the immune response to vaccines, weight gain and overall performance of birds remains poor. However, studies in mice and human have shown that early-life modulation of microbiota colonization by antibiotics could result in the development of immunitybased disorders, such as asthma and allergy [25].

Surveys conducted in some parts of Nigeria have revealed that antibiotics mostly given to day-old chicks belong to the aminoglycosides and tetracyclines $[4,19]$, therefore in this study we selected gentamicin (a broadspectrum aminoglycoside) and doxycycline (a member of the tetracycline class of antibiotics); both having broadspectrum antimicrobial activity $[10,23]$.

\section{MATERIALS AND METHODS}

\section{Experimental animals}

One hundred unvaccinated day-old broiler chicks (Anak $2000^{\oplus}$; Amo Farm Sieberer, Awe, Oyo State, Nigeria) were used for this study. The birds were raised intensively on deep litter, in standard poultry pens located at the Department of Veterinary Physiology and Pharmacology, Michael Okpara University of Agriculture, Umudike, Nigeria, between November and December of 2018. Using wood and wire gauze, the pen was uniformly divided into four partitions, each measuring $3.66 \times 1.83 \mathrm{~m}$.

Twenty-four hours prior to the chicks' arrival, the pen was heated to $33^{\circ} \mathrm{C}$ and maintained at the same tempera- ture throughout the first week. Subsequently, the brooding temperature was reduced by $3^{\circ} \mathrm{C}$ weekly until the 4 th week, when the source of heat was removed and the birds were maintained at an ambient temperature $\left(22-25^{\circ} \mathrm{C}\right)$. The birds were exposed to 24 hours of light throughout the experimental periods and fed ad libitum with commercial broiler starter (Top feed ${ }^{\circledR}$, Nigeria). They were allowed free access to drinking water, except 1 hour prior to the vaccinations. The ethical standards governing the use of live animals for experiments as stipulated by $\mathrm{Z}$ i m e r m a n [31], $\mathrm{W}$ a r d and E 1 s e a [29] were strictly observed. The protocol for this study was approved by the College of Veterinary Medicine, Michael Okpara University of Agriculture, Umudike Research Ethics Committee, and was assigned the approval number: MOUAU/CVM/2018/003.

\section{Experimental design}

Upon arrival, the birds were randomly assigned to four groups $(n=25)$. Birds in group 1 served as a control and received plain water. Group 2 birds were given gentamicin (Gentamicin ; Greenlife Pharmaceuticals Ltd., Lagos, Nigeria) only, while birds in group 3 were treated with a combination of gentamicin and doxycycline (Doxygentavet ${ }^{\circledR}$; Interchemie werken, Venray, Holland). The birds in group 4 received doxycycline only. All of the drugs were given at therapeutic doses, in drinking water for 5 consecutive days (days 2-6), following the manufactures' specifications. On day 18, the chicks were given ND-LaSota vaccine (ORNIPEST $^{\circledast}$; Bioveta, Czech Republic), via the intra-ocular route.

\section{Sample collection}

On the 18th day (prior to the ND-LaSota vaccinations) $2 \mathrm{ml}$ of blood was collected from the wing vein of each of 4 birds randomly selected from each group. The blood was delivered into plain sample bottles, allowed to stand in a slanting position for 30 minutes, and then centrifuged at $2500 \mathrm{rpm}$. The harvested sera were stored in the freezer $\left(-20^{\circ} \mathrm{C}\right)$ until the time of use. Following this procedure, blood samples were collected from the birds and the sera were harvested at weekly intervals for four consecutive weeks. The birds that were sampled were properly identified so that no chick was bled more than once.

\section{Preparation of $1 \%$ chicken red blood cells (RBC)}

Two millilitres of blood was collected from the wing 
vein of 3 unvaccinated chickens housed separately from the experimental birds. The blood samples were delivered into test-tubes containing equivalent volumes of Alsever's anticoagulant and pooled. The sample was centrifuged at $1500 \mathrm{rpm}$ for 5 minutes, the supernatant discarded, then replaced with phosphate buffered saline (PBS) and centrifuged again. This procedure was repeated thrice, then $1 \%$ v/v suspension of the chicken RBC was achieved by adding $20 \mathrm{ml}$ of PBS to $200 \mu \mathrm{l}$ of washed RBC [22].

\section{Preparation of virus antigen}

The antigen was prepared from ND-LaSota vaccine $\left(\right.$ ORNIPEST $^{\oplus}$ ) by reconstituting a 200 -dose vial of the vaccine in $2 \mathrm{ml}$ of PBS, at $\mathrm{pH} 7.4$ [3].

\section{Determination of the haemagglutination titre} of the antigen

This was done following the protocol of OIE [18], as described by Ali [2].

Phosphate buffered saline $(25 \mu \mathrm{l})$ was placed into each well of a plastic V-bottomed 96-well microtitre plate.

The virus suspension $(25 \mu \mathrm{l})$ was placed in the first well and twofold dilutions of $25 \mu \mathrm{l}$ volumes of the virus suspension were made across the plate.

A further $25 \mu \mathrm{l}$ of PBS was dispensed to each well, then $25 \mu \mathrm{l}$ of the $1 \%$ chicken RBC was added to each well. The plate was gently tapped for proper mixing, then held for 40 minutes at room temperature.

The hemagglutination was determined by tilting the plate and observing the presence or absence of tear-shaped streaming of the RBCs. The highest dilution that gave a complete HA (no streaming) was taken as the HA titre, and represents $1 \mathrm{HA}$ unit (HAU).

\section{Hemagglutination inhibition (HI) test}

Phosphate buffered saline $(25 \mu \mathrm{l})$ was placed into each well of a plastic V-bottomed 96-well microtitre plate.

Serum $(25 \mu \mathrm{l})$ was placed in the first well and twofold dilutions of $25 \mu \mathrm{l}$ volumes of the serum were made across the plate.

Twenty-five microlitres of $4 \mathrm{HAU}$ virus/antigen were added to each well and the plate was kept for 30 minutes at room temperature.

Twenty-five microlitres of $1 \%(\mathrm{v} / \mathrm{v})$ chicken RBCs were added to each well. After gentle mixing, the RBCs were allowed to settle for 40 minutes at room temperature.
The highest dilution of serum causing complete inhibition of $4 \mathrm{HAU}$ of antigen was taken as the HI titre. The agglutination was determined by tilting the plate and observing the presence or absence of tear-shaped streaming of the RBCs [18].

\section{Live weight and feed conversion efficiency (FCE)}

Upon the arrival of the birds, their live weights were determined using a digital balance. Subsequently, they were weighed every week. At the end of the 6-week experimental period, the FCE of each group of birds was calculated using the formula:

$$
\mathrm{FCE}=\frac{\text { weight gain }}{\text { feed intake }} \times 100
$$

\section{Statistical analysis}

The data obtained were presented as means \pm SEM and analysed using one-way analysis of variance (ANOVA) (SPSS software, version 20). The variant means were separated by the least significant difference (LSD) of the different groups. Significance was accepted at the level of $\mathrm{P}<0.05$.

\section{RESULTS}

The effect of early-life exposure of broiler chicken to gentamicin and doxycycline antibiotics on Newcastle disease virus antibody titre

The results showed that at week 0 (i.e. before ND-LaSota vaccinations), the ND antibody titre across the groups ranged between $1.75 \pm 0.25$ and $2.00 \pm 0.48$ [ $\log 2$ geometric mean titre (GMT)]. It significantly increased and peaked at the 3 rd week post-vaccination ( $5.25 \pm 0.48-5.75 \pm 0.25)$, after which it recorded a decline in all of the groups. However, throughout the experiments there were no significant $(\mathrm{P}<0.05)$ differences between the antibody titre of the antibiotic-treated birds, when compared to those of the control (Table 1).

Effect of early-life gentamicin and doxycycline administration on the live weight, weight gain and feed conversion efficiency of broiler chickens

From the 4 th to 6 th week, there was a significant $(\mathrm{P}<0.05)$ increase in the live weight of the control when compared to the antibiotics-treated groups (Fig. 1). There 
Table 1. Newcastle disease virus antibody titre of broiler chicken exposed early to gentamicin and doxycycline antibiotics

\begin{tabular}{|c|c|c|c|c|c|c|}
\hline \multirow{2}{*}{ Groups } & \multirow{2}{*}{ Treatment } & \multicolumn{5}{|c|}{ NDV antibody titre (log2 GMT) } \\
\hline & & Week 0 & Week 1 & Week 2 & Week 3 & Week 4 \\
\hline 1 & Water & $1.75 \pm 0.25$ & $3.75 \pm 0.25$ & $5.50 \pm 0.29$ & $5.75 \pm 0.25$ & $4.75 \pm 0.25$ \\
\hline 2 & Gentamicin & $1.75 \pm 0.25$ & $3.75 \pm 0.29$ & $5.50 \pm 0.29$ & $5.75 \pm 0.25$ & $4.50 \pm 0.50$ \\
\hline 3 & $\begin{array}{l}\text { Gentamicin + } \\
\text { Doxycycline }\end{array}$ & $2.00 \pm 0.48$ & $4.00 \pm 0.41$ & $5.55 \pm 0.25$ & $5.25 \pm 0.48$ & $4.75 \pm 0.25$ \\
\hline 4 & Doxycycline & $2.00 \pm 0.48$ & $3.50 \pm 0.65$ & $5.00 \pm 0.41$ & $5.50 \pm 0.29$ & $4.75 \pm 0.25$ \\
\hline
\end{tabular}

Table 2. Effects of early-life gentamicin and doxycycline administration on the live weight and feed conversion efficiency of broiler chickens

\begin{tabular}{|c|c|c|c|c|c|c|}
\hline Groups & Treatment & $\begin{array}{l}\text { Live weight }[\mathrm{kg}] \\
\text { Day } 1\end{array}$ & Feed intake $[\mathrm{kg}]$ ) & $\begin{array}{l}\text { Live weight }[\mathrm{kg}] \\
\text { Day } 42\end{array}$ & Weight gain [kg] & $\begin{array}{c}\text { Feed conversion } \\
\text { efficiency [\%] }\end{array}$ \\
\hline 1 & Water & $0.041 \pm 0.002$ & 3.06 & $2.39 \pm 0.14$ & 2.349 & 76.7 \\
\hline 2 & Gentamicin & $0.039 \pm 0.001$ & 3.09 & $2.03 \pm 0.11^{*}$ & $1.991^{*}$ & 64.4 \\
\hline 3 & $\begin{array}{l}\text { Gentamicin + } \\
\text { Doxycycline }\end{array}$ & $0.037 \pm 0.001$ & 3.09 & $2.09 \pm 0.04^{*}$ & $2.053^{*}$ & 66.4 \\
\hline 4 & Doxycycline & $0.040 \pm 0.001$ & 3.09 & $2.21 \pm 0.07^{*}$ & $2.170^{*}$ & 70.2 \\
\hline
\end{tabular}

*-P $<0.05$ when compared with control

was also a significant $(\mathrm{P}<0.05)$ increase in the weight gain of the control when compared to those of the antibioticstreated birds. This was reflected in the $76.7 \%$ FCE in the control group, against $64.4,66.4$ and $70.2 \%$ FCE in the groups that received gentamicin alone, gentamicin + doxycycline and doxycycline alone, respectively (Table 2).

\section{DISCUSSION}

The haemagglutination inhibition test is the method of choice for the assessment of the immune response to the ND vaccines in birds $[2,22]$; therefore it was employed in this study for the determination of the antibody titre following the ND-LaSota vaccinations. The low NDV antibody titre recorded at week 0 (before the LaSota vaccinations) was a reflection of waning maternal antibodies in the chicks $[7,24]$. The significant increases in antibody titre (> $\log 23.0)$ in all of the groups 2 weeks post-vaccination revealed that the ND-LaSota vaccine triggered positive (protective) immune responses to the Newcastle disease virus in the chicks $[3,18]$.

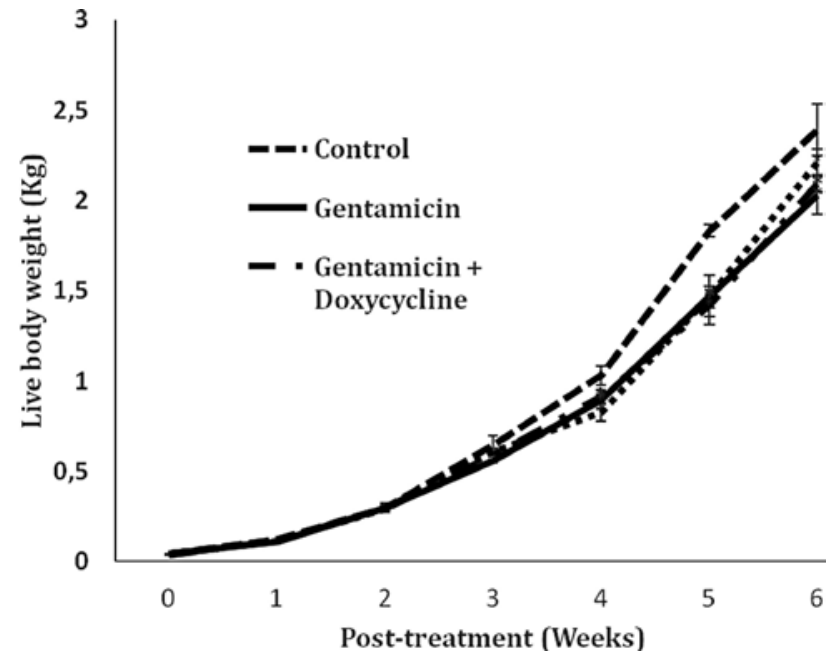

Fig. 1. Effect of early-life gentamicin and doxycycline on the live weight of broiler chickens ${ }^{*} \mathrm{P}<0.05$ when compared with control

The non-significant difference $(\mathrm{P}>0.05)$ in NDV antibody titre between the control and the other test groups demonstrated that early-life (day 2-6) administration of gentamicin and doxycycline to broiler chickens did not 
of the gut microbiota between the termination of antibiotics administration (day 6) and the ND-LaSota vaccinations (day 18). S i m o $n$ et al., [27] reported the recovery of the faecal microbiota composition of antibiotic-treated birds 2 weeks after cessation of the antibiotic administration. In our research, the antibiotics schedule (days 2-6) was aimed at mimicking common poultry production practice (in Nigeria) of brooding young chicks with broad spectrum antibiotics within their first week of life. The ND-LaSota vaccine was not administered until day 18 in order to allow for the decay of the maternal antibodies which would have interfered with the vaccine [24].

The significant increase in live weight, weight gain, and feed conversion efficiency of the control group compared with the antibiotic-treated groups may have resulted from the additional metabolic functions which the microbiome provided for the host chicken [20]. These functions include: nutrient absorption and utilization, fermentation of non-digestible dietary fibre, synthesis of bile acids, and scavenging of free radicals $[6,8,16,28]$.

\section{CONCLUSIONS}

We concluded that the exposure of broilers to gentamicin and doxycycline within their first week of life did not modulate immune response to the Newcastle disease LaSota vaccination carried out 12 days after terminating the antibiotics administration. However, the live weight, weight gain and feed conversion efficiency of the antibiotics-treated birds were significantly lower than those of the control.

\section{ACKNOWLEDGEMENTS}

We acknowledge the assistance of Dr. Empress Oyongwo and Mr. David Johnson in taking care of the birds. They also helped to restrain them for sample collections. We are grateful to Dr. Franklin Iwuamadi for rendering technical support during the serological evaluations.

\section{REFERENCES}

1. Adene, D. F., 2008: Poultry Health and Production: Principles and Practices. Ibadan, Stirling-Horden Publishers Ltd., 3-11.

2. Ali, H. H., 2015: Study of serologic status of Newcastle disease in broiler chickens by hemagglutination inhibition test in Suliamania Province. Glob. J. Bio-Sci. Biotechnol., 4, 4, 364-369.

3. Ambali, H. M., Nwoha, R. I. O., Abdu, P. A., 2017: Evaluation of antibody response to Newcastle disease vaccination in chickens in some commercial farms in two Local Government Areas in Lagos State, Nigeria. J. Vet. Med. Surg., 1, 2, 1-6. DOI: $10.4172 / 2574-2686.100010$.

4. Awogbemi, J., Adeyeye, M., Akinkunmi, E. O., 2018: A survey of antimicrobial agents usage on poultry farms and antimicrobial resistance in Escherichia coli and Staphylococci isolates from the poultry in Ile-Ife, Nigeria. J. Infect. Dis. Epidemiol., 4, 1, 1-8. DOI: 10.23937/2474-3658/1510047.

5. Chung, H., Pamp, S. J., Hill, J. A., Surana, N. K., Edelman, S. M., Troy, E. B., et al., 2012: Gut immune maturation depends on colonization with a host-specific microbiota. Cell, 149, 7, 1578-1593. DOI: 10.1016/j.cell.2012.04.037.

6. Cisek, A. S., Binek, M., 2014: Chicken intestinal microbiota function with a special emphasis on the role of probiotic bacteria, Pol. J. Vet. Sci., 17, 2, 385-394. DOI: 10.2478/pjvs2014-0057.

7. Czifra, G., Meszaros, J., Horvath, E., Moving, V., Engstrom, B. E., 2007: Detection of NDV-specific antibodies and the level of protection provided by a single vaccination in young chickens. Avian Pathol., 27, 6, 562-565. DOI: 10.1080/ 0307945980849384.

8. Daniel, B. M., Jana, S., Amelia, C. S., 2018: Current perspectives of the chicken gastrointestinal tract and its microbiome. Comput. Struct. Biotechnol. J., 16, 131-139. DOI: 10.1016/j. csbj.2018.093.002.

9. Gomez de Aguero, M., Ganal-Vonarburg, S. C., Fuhrer, T., Rupp, S., Uchimura, Y., Li, H., et al., 2016: The maternal microbiota drives early postnatal innate immune development. Science, 351, 1296-1302.

10. Harvey, R. A., Champe, P. C., 2009: Pharmacology. 4th edn., New Delhi, Wolters Kluwer Pvt, 387-390.

11. Honda, K., Littman, D. R., 2016: The microbiota in adaptive immune homeostasis and disease. Nature, 535, 75-84. DOI: $10.1038 /$ nature 18848 .

12. Kabat, A. M., Srinivasan, N., Maloy, K. J., 2014: Modulation of immune development and function by intestinal mi- 
crobiota. Trends Immunol., 35, 507-517. DOI: 10.1016/j.it. 2014.07.010.Epub2014Aug27.

13. Lu, J. R., Idris, U., Harmon, B., Hofacre, C., Maurer, J. J., Lee, M. D., 2003: Diversity and succession of the intestinal bacterial community of the maturing broiler chicken. Appl. Environ. Microbiol., 69, 11, 6816-6824. DOI: 10.1128/ aem.69.11.6816-6824.2003.

14. Lynn, M. A., Tumes, D. S., Choo, J. M., Wesselingh, S. L., Rogers, G. B., Lynn, D. J., 2018: Early-life antibiotic-driven dysbiosis leads to dysregulated vaccine immune responses in mice. Cell Host Microbe, 23, 653-660. DOI: 10.1016/j.chom. 2018.04.009.

15. Maynard, C. L., Elson, C. O., Hatton, R. D., Weaver, C. T., 2012: Reciprocal interactions of the intestinal microbiota and immune system. Nature, 489, 7415, 231-241. DOI: 10.1038/ nature11551.

16. Oakley, B. B., Lillehog, H. S., Kogut, M. H., Kim, W. K., Maurer, J. J., Pedroso, A., 2014: The chicken gastrointestinal microbiome. FEMS Microbiol. Lett., 360, 100-112. DOI: 10. 1111/1574-6968.12608.

17. Ohimain, E. I., Ofongo, R. I., 2012: The effect of probiotic and probiotic feed supplementation on chicken health and gut microbiota: a review. Int. J. Anim. Vet. Adv., 4, 2, 135-143.

18. OIE, 2012: Newcastle disease. In Manual of Diagnostic Tests and Vaccines for Terrestrial Animals, 7th edn., Vol. 1, Chapter. 2.3.14. World Organisation for Animal Health (OIE), $555-574$.

19. Oluwasile, B. B., Agbaje, M., Ojo, O. E., Dipeolu, M. A., 2014: Antibiotic usage pattern in selected poultry farms in Ogun State. Sokoto J. Vet. Sci., 12, 1, 45-50. DOI: 10.4314/ sokivs.v12i1.7.

20. Praharaj, T., John, S. M., Bandyopadhyay, R., Kang, G., 2015: Probiotics, antibiotics and the immune response to vaccines. Phil. Trans. B, 370, 20140144. DOI: 10.1098/rstb. 2014.0144 .

21. Qureshi, I. Z., Razzaq, A., 2017: Antibiotics restricted alteration in gut microbiota and compromised immunity in broiler chickens. Appr. Po. Da. Vet. Sci., 1, 4, 000516. DOI: 10.31031/ APDV.2017.01.000516.
22. Rahman, M. M., Sarker, R. D., Mohammed, N., 2017: Evaluation of serum antibody titre level against Newcastle disease virus in vaccinated broiler chickens. AVAS, 4, 3, 94-98.

23. Rang, H. P., Dale, M. M., Ritter, J. M., Flower, R. J., 2007: Rang and Dale's Pharmacology. 6th edn., Churchill Livingstone/Elsevier, Philadelphia, 665-674.

24. Saad, G., Kamel, M., 2013: Decay of maternal antibodies in broiler chicken. Poultry Sci., 92, 2333-2336. DOI: 10.3382/ ps.2013-03249.

25. Schokker, D., Jansman, A. J. M., Veninga, G., Bruin, N., Vastenhouw, S. A., Bree, F. M., et al., 2017: Perturbation of microbiota in one-day old broiler chickens with antibiotic for 24 hours negatively affects intestinal immune development. BMC Genomics, 18, 241. DOI: 10.1186/s12864-017-3625-6.

26. Sharif, A., Ahmad, T., 2018: Preventing Vaccine Failure in Poultry Flocks. Retrieved November 9, 2018, from Google scholar data base on the World Wide Web: http://dx.doi.org/ 10.5772/intechopen.79330.

27. Simon, K., Verwoolde, M. B., Zhang, J., Smidt, H., de Vries Reilingh, G., Kemp, B. and Lammers, A., 2016: Long-term effects of early life microbiota disturbance on adaptive immunity in laying hens. Poultry Sci., 95, 1543-1554. DOI: 10. 3382/ps/pew088.

28. Slawinska, A., Denislawska, A., Plowiec, A., Radomska, M., Lachmanska, J., Siwek, M., et al., 2019: Modulation of microbial communities and mucosal gene expression in chicken intestines after galactooligosaccharides delivery in ovo. PLoS ONE, 14, 2, e0212318. DOI: 10.1371/journal.pone.0212318.

29. Ward, J. W., Elsea, S. R., 1997: Animal case and use in drug fate and metabolism. In Methods and Techniques, Vol. 1., Marcel Dekker, New York, 372-390.

30. Woo, P. C. Y., Tsoi, H., Wong, L., Leung, H. C. H., 1999: Antibiotics modulate vaccine-induced humoral immune response. Clin. Diagn. Lab. Immunol., 6, 6, 832-837.

31. Zimmermann, M., 1983: Ethical guidelines for investigations of experimental pain in conscious animals. Pain, 16, 2, $109-110$.

Received March 30, 2020

Accepted June 6, 2020 